\title{
Chapter 24 \\ Outcomes and Recommendations \\ from the 12th International Sago Symposium
}

\author{
Yoshinori Yamamoto
}

\begin{abstract}
The 12th International Sago Symposium took place in Tokyo, Japan, in 2015. This chapter reviews the recent and advanced information presented at the symposium. All symposium presentations are categorized under eight topics and summarized, and the outcomes and recommendations described.
\end{abstract}

\subsection{International Sago Symposium}

Since the First International Sago Symposium was held in Kuching in 1976, a sago symposium has been convened each 2-6 years thereafter, and the 12th International Sago Symposium took place in Tokyo (venue: Ikebukuro Campus of Rikkyo University) in 2015. The countries where the symposia have been held are those where sago palms grow, such as Malaysia, Thailand, Indonesia, Papua New Guinea, and the Philippines, except Japan. In Japan, the sago palm and sago research were promoted by the enthusiastic efforts of the late Dr. Isao Nagato who provided financial support to fund the Society for the Sago Palm and Sago Culture (presently the Society of Sago Palm Studies) in 1992 and for young Japanese researchers to conduct sago palm research in the sago palm-growing countries. Dr. Nagato also gave financial support to international sago symposia not only in Japan but also in other countries. The research results from Japan and the Southeast Asian countries have been presented at the annual meeting of the Society of Sago Palm Studies and the papers published in the Society's journal SAGO PALM. In 2010, the research results appeared in the publication of Sagoyashi (in Japanese) (Kyoto University Press), and in 2015 the English version The Sago Palm (Kyoto University Press and Transpacific Press) was published with the financial support of the Japan Society for Promotion of Science.

In this chapter, first, all the presentations at the 12th International Symposium are summarized (The Society of Sago Palm Studies 2015) and categorized under seven topics to share the information presented at the symposium, and then the

Y. Yamamoto $(\square)$

Kochi University, Nankoku, Kochi, Japan

e-mail: yamayosi@kochi-u.ac.jp 
outcomes and recommendations are described. Some of the presentations are included in this book, providing more information. Please refer to the proceedings (Ehara et al. 2016) for more information about the presentations not included in this book.

\subsection{Summaries of Presentations at the 12th International Sago Symposium}

\subsubsection{Sago as a Resource in Its Growing Areas}

Jong (Malaysia) reviewed the changes in the scale of processing and starch extraction techniques of sago starch factories, starch production rates, and utilization of sago starch in Malaysia and Indonesia from the 1980s to 2015. He also reviewed the development of sago palm plantations established in Selat Panjang, Riau, and conversion of wild sago forests into sago plantations in South Sorong, West Papua, Indonesia, based on his experience related to those developments. He concluded that sago plantation development and industrialization of sago factories are considerably behind in realizing their potentials and upcoming actions should be implemented in a way to be attractive to future investors.

Mofu and Abbas (Indonesia) of the University of Papua founded the Sago Palm Research Consortium (SPRC) which includes governmental organizations and the private sector to promote the industrial utilization of sago palm, which is the traditional starch crop in Papua. They reported on mechanization trials of starch extraction, utilization of sago starch as ingredients in various kinds of cakes and cooked dishes, to make feedstock for fish, etc. Haska (Indonesia) reported the necessity of sustainable development of the natural sago forests in Papua, considering preservation of the ecosystem and biodiversity in view of the increased interest in sago palm as a profitable business commodity in recent years. Quevedo and Lina (Philippines) reviewed the history of sago palm research in the Philippines and the current status of sago palm-growing areas and utilization. Sago palm research in the Philippines began in Mindanao, at the University of Philippines Mindanao, where sago palm grows, followed by the Visayas area (Aklan State University). Considering the current status of sago palm-growing areas, they proposed the need to develop sago palm plantations to assure that enough raw materials would be available for starch extraction if the industrialization of sago palm proceeds later in the Philippines. Pue et al. (PNG) reported that the consumption of sago starch as a staple food in PNG is decreasing, brought about by the introduction of new staple crops, such as rice, to PNG and the misunderstanding of sago palm in relation to hemolytic disease. He pointed out the importance of sago palm in the future as a staple food in PNG, especially in the areas where high population increase is predicted and crop yields are low due to limited areas of fertile soils. Sago is also important from the viewpoint of food security caused by climate change. 
Watling (Fiji) reported about Metroxylon vitiense traditionally growing in Fiji since ancient times, which is rapidly decreasing in population through clearance of land for agriculture, fires, large-scale coastal drainage schemes, and residential development; the palm is now restricted to less than 20 isolated populations. Moreover, in the past 20 years, populations continue to decrease due to the utilization of leaves for roofing materials for tourism structures and tree destruction for palm heart consumption. To preserve the palm under these conditions, a species recovery plan was agreed to and is being implemented by landowners, government agencies, and users.

Djodikusumo et al. (Indonesia) estimated the annual potential sago starch production in Papua at 150 million $\mathrm{mt}$ ( 500 million ha $\times 30 \mathrm{mt} / \mathrm{ha} / \mathrm{year}$ ) which theoretically could sustain 1.5 billion people ( $100 \mathrm{~kg} \mathrm{starch} / \mathrm{capita} / \mathrm{year})$; therefore, the sago forests in Papua are significant not only to Indonesia but also represent a world asset. However, to realize this there need to be policies to prevent conversion of natural sago forests to agricultural land for other crops and to develop modern equipment for starch extraction and drying to reduce labor requirements. Wulan et al. (Indonesia) carried out a sustainability analysis of three food commodities, rice, oil palm, and sago palm, on peat land. The analysis consisted of environmental analysis using a life cycle assessment (LCA), an economic analysis with environmental life cycle costing (LCC), a social analysis using social life cycle assessment (SLCA), a sustainability assessment using life cycle sustainability dashboard (LCSD), and a life cycle sustainability assessment (LSSA). The results revealed that sago palm is the most sustainable commodity among the three crops cultivated on peat land.

Hasada (Japan) examined the economics of sago starch production at the cottageindustry level using semi-cultivated sago stands and the possibility and constraints of expanding sago starch production in Southeast Sulawesi, Indonesia. The results suggest that, in order to succeed in promoting the sago starch production industry, the following concerns must be addressed: (1) diversification of market channels to expedite stable income generation, (2) provision of financial services that promote capital investment, and (3) development or improvement of processing equipment and overhaul of the current sago palm cultivation and utilization systems to reduce labor needs. Girsang et al. (Indonesia) discussed the possibility of enlargement of starch factories in Seram and Ambon Islands, Maluku Province, Indonesia, comparing the current small-scale sago factories with traditional, semi-modern, and modern technologies. The results revealed that the modernization of sago factory promoted starch production, labor absorption, and profit, but it was difficult to sustain because of raw material preparation, uncertain market demand, and fragile institutional development. 


\subsubsection{Diversity of Sago Resource in Asia and Pacific}

Johnson (USA) reviewed the history, geographic distribution, habitat characteristics, and classification of the palms of the genus Metroxylon. Ehara et al. (Japan) reported on the geographic distribution, starch productivity, and current status of utilization of the palms belonging to the Metroxylon and Coleococcus sections of Metroxylon. The report showed that the starch productivity of the palms belonging to the Coleococcus section were lower than those of Metroxylon. Moreover, the genetic diversity of sago palms growing in the eastern areas of the Malay Archipelago was greater than that of the western areas. The study used the RAPD (random amplified polymorphic DNA) method and divided the sago palms of the Malay Archipelago into four broad groups. Abbas et al. (Indonesia) recognized the intraspecific variation among 11 accessions collected in Papua Province, Indonesia, through the DNA analysis of the mitochondrial genome. Moreover, Matanubun (Indonesia) and Dewi et al. (Indonesia) reported the morphological differences among the sago palm folk varieties growing around Lake Sentani, Papua, Indonesia, and the relationship between the genetic differences and starch productivity among 12 accessions of wild sago palms growing in South Sorong, West Papua, Indonesia, respectively. In addition, Bilbao and Novero (Philippines) researched the genetic difference between suckering and non-suckering sago palms by SSR (simple sequence repeat) analysis, applying the primer sets used to establish genetic differences in date palm. Also, Ibrahim et al. (Malaysia) reported the minimal inhibitory concentration of Basra ${ }^{\mathrm{TM}}$, as a selection agent of transformed cells, for the sago palm transformant selection in the future.

\subsubsection{Agricultural Botany of Sago Palm}

Nakamura et al. (Japan) analyzed the growth pattern of sago palm suckers after transplanting and divided the growth pattern into three stages: (1) creeping (horizontally elongating) growth stage (4-5 years), (2) transition (shifting) growth stage from horizontal to vertical (1-1.5 years), and (3) trunk elongation (vertical) growth stage (6-7 years). Nabeya et al. (Japan), from the same research group in Nakamura (Japan), showed the same growth pattern of suckers emerging from the mother stem (primary suckers) and the suckers emerging from the primary suckers (secondary suckers) as the mother stem, as shown by Nakamura. Besides, they showed that the horizontal growth rate of the stem was closely related to the leaf production rate and that the rates were slower with the increasing order of suckers. Miyazaki et al. (Japan) reported the differences of root development (root weight at different vertical and horizontal positions from the palm trunk) by palm age, growing regions, and varieties. The total root weight and the root weight ratio of deep soil layers increased with palm age, and varietal differences in root weight at the same growth stage were clearly observed. 
Yamamoto (Japan) reported the total biomass production and of each part or organ of shoots (aboveground part) in two sago palm varieties growing in Southeast Sulawesi, Indonesia, with palm age and factors related to biomass production, that is, leaf area, photosynthetic rate of leaf, and growth duration. The results revealed that the varietal difference in biomass production is closely related to the leaf area per palm, and it was mainly determined by the leaf area per leaf compared to the number of leaves. Moreover, the leaflet width contributed most to the leaf area per leaf. Based on these data, he analyzed the varietal difference in starch production from the viewpoints of biomass production, distribution ratio to harvesting portion (pith), and starch percentage in pith. The varietal difference in starch production is mainly based on the difference in biomass production.

Delima et al. (Philippines) and Acaso (Philippines) reported research on embryo culture of sago palm seeds. Delima et al. succeeded in producing plantlets by embryo culture irrespective of the degree of seed maturity and seed size. Acaso et al. obtained plantlets with $10.5 \mathrm{~mm}$ shoots and $13.5 \mathrm{~mm}$ roots after 4 weeks by embryo culture under one-half MS medium with kinetin (3 mg/L) + ABA $(0.01 \mathrm{mg} / \mathrm{L})+\mathrm{GA}(0.1 \mathrm{~m} / \mathrm{L})$.

To determine the tolerance of sago palm to high Al concentration in soil, Chuchimanukul et al. (Japan) grew sago palm seedlings under different $\mathrm{Al}$ concentrations in the medium $(0,150,300 \mathrm{ppm})$. The results showed that the top growth was not affected by $\mathrm{Al}$ concentrations at 8 weeks after treatment, but the root growth was severely affected, the diameter decreased, and color darkened with the increase of $\mathrm{Al}$ concentration. From these results they concluded that a high concentration of $\mathrm{Al}$ in soil first affects root growth, in the early growth stage.

In addition, Amarillis et al. (Indonesia) and Ahyuni et al. (Indonesia) reported the effects of sucker size and plant hormones on the early growth of suckers and the effects of nursery periods on the early growth of suckers, respectively.

\subsubsection{Growth Environment}

Mori et al. (Japan) and Sasaki et al. (Japan) reported on microclimatic and soil environmental effects on the conversion of wild sago palm forests into sago palm plantations, respectively, as initial findings. For the microclimatic changes, air temperature, humidity, wind direction, and air pressure in the wild sago forests were compared with those in an open field. Light absorption, transmittance and reflectance, and soil moisture was monitored in the wild sago palm forests. For the soil environment, changes of peat thickness, underground level, soil subsidence, decomposition rate of organic matter, and so forth, after development of wild sago forests, were measured.

Yusuf et al. (Malaysia) analyzed growth results and starch production of sago palms cultivated on deep peat soil; Anderson series 3 ( $>2 \mathrm{~m}$ peat depth), in relation to the sago palm plantation development in Sarawak, Malaysia (LCDA/PERITA 19,063 ha), could not grow well even with fertilizer application. In the experiments, 
suckers grown under the same conditions were planted on the deep peat ( $>5 \mathrm{~m}$ peat depth) and mineral soils, with the thinning of suckers and application of sufficient fertilizer following $\mathrm{P}^{32}$ isotope experimental procedures. Consequently, the sago palm suckers growing on the peat soil showed good growth, comparable to those growing on mineral soil, but growth was gradually retarded after 5 years, and only $36 \%$ of palms (cf. 100\% on mineral soil) reached harvesting stage and had starch yields of only $20 \mathrm{~kg}$ starch yield (cf. starch yield of sago palms grown on mineral soil of $150 \mathrm{~kg}$ per palm). From these results, it was concluded that it is impossible to cultivate sago palms economically on peat soil; cultivation should be restricted to mineral and shallow peat soils.

Watanabe et al. (Japan) estimated the carbon balance within a sago palm garden on peat soil in Sarawak, Malaysia, through the comparison of carbon income by carbon fixation by sago palms and weeds and carbon supply to the soil by fallen leaves and carbon expenditure by emission of carbon dioxide and methane from the soil. Results revealed that the carbon expenditure was higher than the carbon income in the peat soil where sago palms were growing.

With regard to the nutrient acquisition of sago palm in relation to microorganisms, there were two papers presented. Toyota and Shrestha (Japan) isolated nitrogen-fixing bacteria from all parts of sago palm and extracted starch; all the isolates preferred simple carbon compounds as their carbon sources and their activities markedly increased when they were co-cultured in starch or hemicellulose medium with starch or hemicellulose-degrading bacteria. On the other hand, Chan (Malaysia) discussed how to change the relationship between the sago palm and the arbuscular mycorrhiza (AM), which contribute to $\mathrm{P}$ absorption, by soil drainage and $\mathrm{P}$ application, and showed the possibility of reducing the colonization of AM due to lower $\mathrm{pH}$ by $\mathrm{P}$ application, although the relationship did not change by the drainage and $\mathrm{P}$ application.

Umemura et al. (Japan) reported that the people living around Lake Blackwater located in the Central Sepik Plain, PNG, where sago palms are growing on peat soil, adapted to the oligotrophic environment through application of minerals such as $\mathrm{Fe}$, especially from well water and mineral-rich plants.

\subsubsection{Development of Technology in Starch Extraction and Utilization}

\subsubsection{Starch Extraction}

Regarding the starch extraction methods in sago palm-growing areas, Nishimura (Japan) pointed out that they changed from the traditional manual method in the original location (New Guinea Island) to an effective mechanical method (the western area of Malay Archipelago), corresponding to the change of utilization from staple food to commercial industrial commodities. Darma et al. (Indonesia) investigated the effect of cylinder teeth density and rotation speed on power requirements 
and specific energy consumption of a cylinder-type sago rasper. The results showed that the power requirements and specific energy consumption increased with higher teeth density and higher cylinder rotation speed.

Supriyanto et al. (Indonesia) and Haryanto et al. (Indonesia) reported on the dry processing of sago starch instead of wet processing. The dry process involves debarking the trunk, chipping the pith into thin strips, drying, sieving, grinding, and cyclone separation. The starch extracted by this method contains a slightly higher fiber content (about 3\%) than that from the wet method (about 1\%), but this method can save great amounts of water and avoid the pollution by waste water; Suprianto et al. called this method Green Technology. The fiber content in flour derived from the dry method could be reduced by yeast fermentation treatment before drying the sago pith to about $1 \%$ fiber content (Harianto et al.).

\subsubsection{Starch Utilization}

Yokota et al. (Japan) tried to utilize sago starch to make udon noodles, a traditional Japanese food usually made from wheat flour, to enable wheat allergy sufferers to eat the noodle. Udon noodles made from sago starch were highly rated for smoothness, stickiness, and sensory quality, although it was assessed to be a harder noodle as compared to the noodles made from rice, wheat, potato, or kudzu flour. In the sensory test evaluation, sago starch noodles were favored when $50 \%$ of the nonglutinous rice flour was substituted.

\subsubsection{Sago Hampas (Waste) Utilization}

According to reports (Shuiling 2006; Yamamoto et al. 2007), about one-half of the starch in sago palm pith is not extracted and gets discarded as hampas without any utilization. Therefore, the intent of researchers to extract the starch from the hampas and to develop its utilization for many purposes is increasing. One paper related to the starch extraction method from sago hampas and four papers related to the utilization of sago hampas were reported. Santosa et al. (Japan) reported that $21 \%$ of starch (dry weight basis of the hampas) was recovered from the sago hampas through wet milling by using a super mass colloidal mill; the physical properties of the starch are the same as those of starch directly extracted from the pith. Sudiana et al. (Indonesia) and Rachmat et al. (Indonesia) reported the possibilities to produce charcoal briquettes and high-quality silica and waste briquette, respectively; the charcoal and waste briquettes could replace fuel wood. Freddy et al. (Indonesia) suggested sago hampas as an appropriate material for making ethanol due to the high content of carbohydrates (82.4\%). Sunarti et al. (Indonesia) reported that the mechanical characteristics of biodegradable foam, in terms of moduli in rupture and in elasticity produced from the sago hampas, were improved through acid modification by soaking the hampas in $0.144 \% \mathrm{HCl}$ solution and methanol. 


\subsubsection{Sago Starch Properties}

Nitta et al. (Japan) used electron microscopic observations to clarify the type, multiplication, size, and distribution of starch in the sago palm pith in relation to its accumulation. Quanytah et al. (Indonesia) reported the characteristics of sago starches collected from 16 accessions in South Sorong, West Papua, including CIE $1976 \mathrm{~L} * \mathrm{a} * \mathrm{~b} *$ color difference, water, ash, fat and amylose contents, granular size of starch, X-ray diffraction, etc.

Okazaki (Japan) reported that the type of crystalline structure of sago palm starch was $\mathrm{C}$ type, containing both A- and B-type crystalline structure, from the X-ray diffraction patterns, and it showed the flexibility of moisture and heating in the gelatinization processes up to $80{ }^{\circ} \mathrm{C}$. In relation to this report, Katsumi et al. (Japan) proposed using the crystalline index (CI) to evaluate the regularity and deficit of crystalline components in starch from the X-ray diffraction. The results showed that the CI of sago starch is lower than that of corn and potato starch and that the CI is related to the gelatinization temperature and retrogradation of starches.

\subsubsection{New Carbohydrate Resources}

Bujang (Malaysia) reviewed long-term research on production of sugars from sago starch and cellobiose production from sago palm leaves. Sago starch can be enzymatically hydrolyzed into sugar with total $(100 \%)$ recovery and the syrup purified using powdered activated charcoal under gravity to remove all impurities and color. The sweetness of the sugar is about 50\% that of glucose. The brown sugar, without removing impurities and color, has health benefits due to the presence of antioxidants (phenols $300 \mathrm{mg} / \mathrm{kg}$ ). Another product, cellobiose, is a pharmaceutical sugar and commands a high price. From these results, he concluded sago palm is a highpotential crop and a substitute for imported cane sugar in Malaysia.

\subsection{Outcomes and Recommendations}

\subsubsection{Sago as Resources in Its Growing Areas}

Recognition of sago palm as a high-potential starch crop (a food energy crop) appears to be making steady progress in the countries where it grows, from the viewpoints of food security in relation to the projected population increase and global climate change. In addition, research on the impact of sago starch industrialization to economic development of rural area is being promoted. Under such circumstances, it is noteworthy that the University of Papua started to mechanize the starch extraction processes and to develop new commodities made from sago starch, 
by organizing the SPRC (Sago Palm Research Consortium). The Consortium is made up of governmental institutions and the private sector in Indonesian Papua, where wild sago palm area are widespread and starch from the palm has long been utilized as a staple food. It is hoped the activities of SPRC are successfully advanced.

\subsubsection{Diversity of Sago Resource in Asia and Pacific}

Many types of sago palms with different morphological characters, starch productivity, etc. are recognized in the sago palm-growing areas, especially in Papua, Indonesia, and in PNG which is considered the center of diversity of the sago palm. However, the ways in which these differences of sago palms are related to genetic makeup are not clear. There is an urgent need to establish varietal criteria in sago palm taxonomy and to clarify the varietal differences of morphological characters, starch yield, etc., under the same growing conditions such as soil type, groundwater level, management of suckers, and so forth, to evaluate properly the varietal differences of these characters.

\subsubsection{Agricultural Botany of Sago Palm}

To harvest sago palms sustainably, there is a need to develop a management system for sago palm gardens. Sucker control is the core technique for developing the management system. The growth patterns of primary and secondary suckers as well as the mother suckers reported in the symposium provide guidance on how to control the suckers. The report, Miyazaki et al. (Japan), on the root system development of sago palm related to palm age also provides useful information to manage water and fertilizer application in a sago palm garden. The report, Yamamoto (Japan), on the changes in biomass and dry matter distribution to each organ or part (above ground) with palm age and the factors related to the biomass production in varieties with different starch productivity provides not only basic valuable information about the development and growth of sago palm but also essential information for breeding high-yielding varieties. Moreover, the establishment of a high-probability technique for embryo culture may contribute to create new varieties and mass production of seedlings of excellent varieties.

\subsubsection{Growth Environment}

The reports, Mori et al. (Japan) and Sasaki et al. (Japan), on microclimatic and soil environmental conditions of wild sago forests are noteworthy in considering the sustainable development during a time when the concerns of governments and 
private companies for the development of wild sago forests is increasing. The report, Watanabe et al. (Japan), of carbon balance in peat soil where sago palms grow provides useful information for the contribution of sago palm-growing areas to greenhouse gas emission in relation to global warming. This environmental research is expected to continue in the representative sago-growing sites for many years following the same methods. The conclusion of the report by Yusuf et al. (Malaysia) that economic cultivation of sago palm is very difficult on deep peat soil $(>5 \mathrm{~m}$ thick) in Sarawak, Malaysia, and should be restricted to mineral and shallow peat soils may affect the future development of sago palm plantations on deep peat soil because it has been believed that sago palm is the only crop which can grow well on deep peat soil and be cultivated economically on the soil without any improvement. The area of peat soil is estimated at about 30 million ha in Southeast Asia (Kyuma 1986) and may differ in depth and physicochemical properties from site to site. Therefore, detailed research into how the soil depth and the physicochemical properties affect the growth and starch yield of sago palm should be conducted in typical deep peat areas in Indonesia, Malaysia, PNG, etc. Studies should also address how to improve deep peat soil as appropriate land for the cultivation of sago palm, based on the results of characteristics of peat soil in the future. Two interesting research studies, Toyota and Shrestha (Japan) and Chan (Malaysia), in relation to sago palm and microorganisms, nitrogen-fixing bacteria, and arbuscular mycorrhiza, were reported at the symposium. These studies show the possibility of nutrient supply to sago palm by the microorganisms, so it is expected to clarify quantitatively the contribution ratio of these microorganisms to the nitrogen and phosphorous absorption of sago palm.

\subsubsection{Development of Technology in Starch Extraction and Utilization}

In relation to starch extraction from sago palm pith, the dry sago flour making method, in which sago flour is produced through the process of drying the pith, crushing the dried pith, and sieving for fibers, as an alternative to the wet extraction method, was called Green Technology, because it makes it possible to avoid pollution from extraction waste water. It appears to be necessary to develop methods to remove the fibers from the flour, for example, by using yeast before drying the pith, as reported by Haryanto et al. (Indonesia), and to clarify the physicochemical properties of the sago flour. Regarding starch extraction from sago hampas (waste), in which one-half of the total amount of starch remains in the pith (Shuiling 2006; Yamamoto et al. 2007), the wet-milling method using a super mass colloidal mill makes it possible to extract a considerable amount of starch from the hampas without deforming the physical properties of the starch. The reports by Indonesian researchers on utilization of sago hampas as a material for fuel and biodegradable plastic show developing interest in sago hampas. Regarding the development of 
sago starch utilization, udon noodles made with sago starch, a traditional Japanese food usually made from wheat flour, enables wheat allergy sufferers to eat the noodle and was rated highly in a sensory test evaluation. It could contribute to develop the utilization of sago starch as an allergy avoidable food material.

\subsubsection{Sago Starch Properties}

The multiplication, distribution, and amount of sago starch in the pith were reported by observations with a scanning electron microscope. In addition, the characteristics of sago starch collected from 16 accessions in South Sorong, West Papua, Indonesia, were reported. It is desirable to clarify the differences of starch characteristics of sago palms growing under different conditions, as well as the varietal differences. The physical characteristic of sago starch from the X-ray diffraction pattern was clarified, and the crystalline index (CI) evaluated the regularity and deficit of crystalline components in starch from the X-ray diffraction, which was proposed to clearly show the differences of characteristics of starches from various crops. Clarification of the relationship between the physical and chemical properties of sago starch to promote the utilization should be performed.

\subsubsection{New Carbohydrate Resources}

The sago starch utilization research group at UNIMAS (University of Malaysia, Sarawak) has succeeded in producing sugars from sago starch and sago hampas and cellobiose from sago leaves. The results showed the possibility of industrialization of sugar production from sago starch in place of cane sugar and cellobiose production from sago leaves as a pharmaceutical sugar of high value.

\subsubsection{Other Palms}

The starch-accumulating palms belong to 12 genera among about 200 genera of the Arecaceae family. However, thus far research has been predominantly focused on palms in the genus Metroxylon, especially sago palm (M. sagu Rottb.). In such circumstances, Ehara et al. (Japan) reported the starch yield of the palms in the Coleococcus section of Metroxylon (M. salomonense, M. warburgii, M. vitiense, M. amicarum) in this Symposium. Ishima et al. (Japan) and Pasolon et al. (Indonesia) reported research on sugar palm (Arenga pinnata Merr.). The former report revealed the maximum starch yield (100-150 kg dry starch/palm) could be harvested at the growth stage from just before the emergence of female and male inflorescences. The latter reports discussed the relationship between the quantity of sap produced and 
growth characters of the palm. The research group organized by Yamamoto has reported the starch yields of several starch-accumulating palms including Arenga microcarpa, Corypha utan, Caryota mitis, as well as sugar palm (Yamamoto 2010, 2015) which was reported by Ishima et al. in this Symposium. The research on starch-accumulating palms, not only sago palm, but also other minor palms, which are adapted to various environmental conditions, need to be assessed for their possible contribution to the food security under the predicted global climate change.

\section{References}

Ehara E, Toyoda Y, Mishima T et al (eds) (2016) Proceedings of the 12th international sago symposium - the sago supports human planet welfare. The sago palm studies, Tokyo, pp 1-161. (CD version)

Kyuma K (1986) Organic soils in wetland forests: tropical peat soils. In: Lowland swamps in Southeast Asia. Tropical Agricultural Research Center, Norin Tokei Kyokai, Tokyo, pp 79-103. (in Japanese)

Shuiling DL (2006) Traditional starch extraction from the trunk of sago palm (Metroxylon sagu Rottb.) in West Seram (Maluku, Indonesia). In: Karafir YP, Jong FS, Fere VE (eds) Sago palm development and utilization: proceedings of the 8th international sago symposium. Universitas Negeri Papua Press, Manokwari, pp 189-200

The Society of Sago Palm Studies (2015) Abstracts of the 12th international sago symposium, Sago Palm 23 (1):4-57

Yamamoto Y (2010) Strategy for bio-fuel, community to world. Res Trop Agric 3:98-102. (in Japanese)

Yamamoto Y (2015) Studies on the productivity of starch accumulating palms in the tropics - miscellaneous palms. Abstract, Meeting of the Crop Science Society of Japan 239:56 (in Japanese)

Yamamoto Y, Omori K, Nitta Y et al (2007) Efficiency of starch extraction from the pith of sago palm: a case study of the traditional method in Tebing Tinggi Island, Riau, Indonesia. Sago Palm 15:9-15

Open Access This chapter is licensed under the terms of the Creative Commons Attribution 4.0 International License (http://creativecommons.org/licenses/by/4.0/), which permits use, sharing, adaptation, distribution and reproduction in any medium or format, as long as you give appropriate credit to the original author(s) and the source, provide a link to the Creative Commons license and indicate if changes were made.

The images or other third party material in this chapter are included in the chapter's Creative Commons license, unless indicated otherwise in a credit line to the material. If material is not included in the chapter's Creative Commons license and your intended use is not permitted by statutory regulation or exceeds the permitted use, you will need to obtain permission directly from the copyright holder.

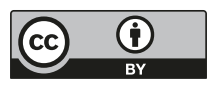

